\title{
ACÚMULO DE SILÍCIO EM PLANTAS DE ARROZ DO ECOSSISTEMA DE VÁRZEA SUBMETIDO À APLICAÇÃO DE DIFERENTES FONTES $\left({ }^{\mathbf{1}}\right)$
}

\author{
LUCÉLIA ALVES RAMOS $\left({ }^{2 *}\right)$; GASPAR HENRIQUE KORNDÖRFER $\left({ }^{3}\right)$; ANTONIO NOLLA $\left({ }^{4}\right)$
}

\begin{abstract}
RESUMO
A baixa produtividade brasileira de arroz decorre, principalmente, da reduzida fertilidade do solo e alta suscetibilidade a algumas doenças. A adubação com silício pode ser uma alternativa no sentido de amenizar, sobretudo, o impacto das doenças sobre a produtividade. No intuito de identificar fontes eficientes quanto ao fornecimento de Si para a cultura do arroz, foi instalado um experimento em vasos, utilizando-se Neossolo Quartzarênico Órtico típico, em delineamento em blocos casualizados. As fontes de Si utilizadas foram siligran e silicon, nas formas granulada e pó, na dose de $200 \mathrm{mg} \mathrm{kg}^{-1} \mathrm{de} \mathrm{Si}$. A curva de resposta a Si foi estabelecida pela aplicação de uma fonte-padrão (Wollastonita) nas doses de 0 , 50, 100, 200, $400 \mathrm{mg} \mathrm{kg}^{-1}$ de Si, visando obter uma curva de resposta. Após a semeadura da cultivar de arroz Rio Formoso, avaliou-se a produção de massa seca da parte aérea, massa de panículas, produção de grãos, Si acumulado na planta e teores de Si no solo. A fonte-padrão Wollastonita apresentou comportamento linear, aumentando o Si disponível no solo e a absorção pelo arroz com o aumento das doses aplicadas. Os maiores aumentos, nos teores de Si na parte aérea, casca, Si acumulado e na massa seca total foram proporcionados pela Wollastonita. A fonte que proporcionou maior aumento na produtividade de grãos foi silicon na forma de pó. O extrator ácido acético extraiu maiores quantidade de Si do solo em relação ao cloreto de cálcio, superestimando os resultados.
\end{abstract}

Palavras-chave: Oriza sativa, silicato de cálcio, adubação.

\section{ABSTRACT SOURCES AND ACCUMULATION OF SILICON IN PLANTS OF LOWLAND RICE}

The low Brazilian productivity of rice is mainly because of the low soil fertility and high susceptibility to some diseases. The fertilization with silicon can be an alternative to decrease the impact of the diseases in the yield. To identify efficient silicon sources for rice, an experiment was installed in pots, using a Quartzipsamment soil, in randomized blocks. The silicon sources used were siligran and silicon, in the forms granulated and powder, in the dose of $200 \mathrm{mg} \mathrm{kg}^{-1}$ of Si. The curve of response to Si was established by application of a standard source (Wollastonite) in the doses of 0, 50, 100, 200, $400 \mathrm{mg}$ $\mathrm{kg}^{-1}$ of $\mathrm{Si}$, seeking to obtain a curve of response. The rice cultivar Rio formoso was sown and the production of dry mass of the aerial part, panicles mass, production of grains, plant tissue and soil Si content, were determined by the rice cycle. The standard source Wollastonite had linear behavior, increasing soil Si availability and its absorption by rice with the increase of the applied doses. The largest increases in the contents of Si in the aerial part, in the peel, and Si accumulated in the plant and Si in the dry total mass were produced by Wollastonite. The source that provided larger increase in the yield of grains was silicon in the powder form. The acetic acid extracted larger amount of Si of the soil than calcium chloride, overestimating the results.

Key words: Oriza sativa, calcium silicate, fertilizer.

$\left({ }^{1}\right)$ Parte da dissertação de mestrado da primeira autora. Recebido para publicação em 15 de Janeiro de 2007 e aceito em 7 de fevereiro de 2008.

$\left({ }^{2}\right)$ Mestre em solos pelo Instituto de Ciências Agrárias da Universidade Federal de Uberlândia - UFU. E-mail: luceliaalvesramos@yahoo.com.br $\left(^{*}\right)$ Autora correspondente.

$\left({ }^{3}\right)$ Instituto de Ciências Agrárias da Universidade Federal de Uberlândia - UFU. Bolsista CNPq. E-mail ghk53@terra.com.br

$\left({ }^{4}\right)$ Centro de Ciências Agrárias, Departamento de Agronomia, Universidade Estadual do Maringá. E-mail: nolla73@hotmail.com 


\section{INTRODUÇÃO}

No Brasil, existem produtos de origem natural ou proveniente da indústria siderúrgica, que podem ser potencialmente aproveitados como fonte de silício para as plantas e em especial para as gramíneas.

Em alguns trabalhos científicos já se constatou a eficiência agronômica de alguns materiais silicatados, entretanto, é necessário investigar e identificar as fontes com maior potencial, observando se essas possuem as seguintes características: altos teores de $\mathrm{Si}$ solúvel, alta reatividade, baixo custo, altos teores de óxido de cálcio $(\mathrm{CaO})$ e óxido de magnésio $(\mathrm{MgO})$, além de baixos teores de metais pesados, em especial para escórias siderúrgicas (KORNDÖRFER et al. 2004a).

O silício é absorvido pelas plantas como ácido monossilícico $\left(\mathrm{H}_{4} \mathrm{SiO}_{4}\right)$, porém seu teor é variável entre as espécies (EPstein, 1994). Atualmente, consideram-se plantas acumuladoras de Si aquelas com teores superiores a $1 \mathrm{~g} \mathrm{~kg}^{-1}$ de Si na massa seca, como arroz e trigo; plantas como soja e cucurbitáceas são consideradas intermediárias, com 0,5 a $1 \mathrm{~g} \mathrm{~kg}^{-1}$ de Si e as plantas não acumuladoras possuem concentração de Si na massa seca inferior a $0,5 \mathrm{~g} \mathrm{~kg}^{-1}$ (MA et al., 2001).

A importância da adubação com silício para as plantas está relacionada principalmente ao aumento da produtividade através de várias ações indiretas, como folhas mais eretas, redução do autosombreamento, tornando os tecidos estruturais mais rígidos e assim reduzindo o acamamento, aumentando a tolerância das plantas à estresses abióticos, como a redução da toxidez de $\mathrm{Fe}, \mathrm{Mn}, \mathrm{Al}$ e $\mathrm{Na}$; diminuição na incidência de doenças e ataque de pragas ( Epstein, 1994; MARSCHNER, 1995).
O arroz é uma das culturas mais responsivas à aplicação de silício e, em alguns países, a adubação com esse elemento já é utilizada em larga escala. No Japão, por exemplo, $25 \%$ da área cultivada com arroz recebem anualmente aplicações de silicato de cálcio que variam de 0,5 a 1,0 tonelada, demonstrando a importância da utilização do Si nesse país.

No Brasil, SAntos et. al (2003), trabalhando com doses crescentes de metassilicato, observaram aumentos significativos na produtividade da cultura do arroz com a maior dose aplicada $\left(6.000 \mathrm{~kg} \mathrm{ha}^{-1}\right)$. Pereira et al. (2004), trabalhando com doses crescentes de Wollastonita na cultura do arroz, em um Neossolo Quartzarênico, obtiveram aumentos na produtividade de grãos de 24,0 $\mathrm{g} \mathrm{vaso}^{-1}$, na testemunha, para $33,0 \mathrm{~g}$ vaso $^{-1}$, na dose equivalente a $500 \mathrm{~kg} \mathrm{ha}^{-1} \mathrm{de} \mathrm{Si}$.

O objetivo deste trabalho foi identificar as fontes que melhor disponibilizam o silício no solo e proporcionam mais crescimento e desenvolvimento da cultura do arroz.

\section{MATERIAL E MÉTODOS}

O experimento foi instalado em casa de vegetação no Instituto de Ciências Agrárias da Universidade Federal de Uberlândia - UFU, utilizando amostra de um Neossolo Quartzarênico Órtico típico (RQo típico), coletado em Santa Vitória (MG), com as características químicas e físicas (Tabelas 1 e 2).

O solo foi seco e peneirado para a incorporação dos tratamentos. Este solo foi escolhido em razão de seu baixo teor de Si $\left(0,6 \mathrm{mg} \mathrm{dm}^{-3}\right)$, o que pode contribuir para a obtenção de melhores respostas em relação à aplicação das fontes de Si.

Tabela 1. Caracterização química do Neossolo Quartzarênico Órtico Típico utilizado no experimento

\begin{tabular}{|c|c|c|c|c|c|c|c|c|c|}
\hline $\mathrm{pH}\left(\mathrm{CaCl}_{2}\right)$ & $P$ & $\mathrm{Si}$ & $\mathrm{Al}$ & $\mathrm{Ca}$ & $\mathrm{Mg}$ & SB & $\mathrm{T}$ & $\mathrm{V}$ & $\mathrm{m}$ \\
\hline $1: 2,5$ & \multicolumn{2}{|c|}{$\mathrm{mg} \mathrm{dm} \mathrm{m}^{-3}$} & \multicolumn{6}{|c|}{$\mathrm{mmol}_{\mathrm{c}} \mathrm{dm}^{-3}$} & $\%$ \\
\hline 4,6 & 1,3 & 0,6 & 7,0 & 1,0 & 1,0 & 1,0 & 47,7 & 5,0 & 74 \\
\hline
\end{tabular}

$\mathrm{Ca}, \mathrm{Mg}, \mathrm{Al}=\left(\mathrm{KCl} 1 \mathrm{~mol} \mathrm{~L}^{-1}\right) ; \mathrm{P},=\left(\mathrm{HCl} \mathrm{0,05} \mathrm{mol} \mathrm{L}^{-1}+\mathrm{H}_{2} \mathrm{SO}_{4} 0,025 \mathrm{~mol} \mathrm{~L}^{-1}\right) ; \mathrm{Si}=\left(\mathrm{CaCl}_{2} 0,01 \mathrm{~mol} \mathrm{~L}^{-1}\right) \mathrm{H}+\mathrm{Al}=$ acidez potencial $($ acetato de cálcio); $\mathrm{T}=\mathrm{CTC}$ à $\mathrm{pH} 7 ; \mathrm{V}=$ Saturação por bases \%; $\mathrm{MO}=($ WALKLEY-BLACK).

Tabela 2.Caracterização textural do Neossolo Quartzarênico Órtico Típico (RQo) utilizado no experimento

\begin{tabular}{lccc}
\hline Areia Grossa & Areia Fina & Silte & Argila \\
\cline { 2 - 4 } & & $\mathrm{g} \mathrm{kg}^{-1}$ & \\
626 & 218 & 1 & 155
\end{tabular}

Análise textural pelo método da pipeta (EMBRAPA, 1999).
As fontes foram pesadas e misturadas ao solo com o auxílio de betoneira, juntamente com o $\mathrm{CaCO}_{3}, \mathrm{o} \mathrm{MgCO}_{3}$ e a adubação básica, que constou da aplicação de $0,2 \mathrm{~g}$ $\mathrm{kg}^{-1}$ sulfato de amônio e supertriplo, $0,12 \mathrm{~g} \mathrm{~kg}^{-1} \mathrm{de} \mathrm{KCl} \mathrm{e}$ $0,1 \mathrm{~g} \mathrm{~kg}^{-1} \mathrm{de}$ um formulado de micronutrientes contendo $9 \% \mathrm{Zn} ; 1,8 \%$ B; $2 \% \mathrm{Mn} ; 0,8 \% \mathrm{Cu} ; 0,1 \% \mathrm{Mo} ; 3 \% \mathrm{Fe}$. O fornecimento de $\mathrm{N}$ e $\mathrm{K}$ foi realizado metade na semeadura e metade após 20 dias. No decorrer do experimento verificou-se deficiência de nitrogênio nas plantas de arroz. Foi realizada, em 29 de junho e 13 de julho de 2004, adubação complementar com uréia na dose de $0,05 \mathrm{~g} \mathrm{~kg}^{-1}$. 
O solo foi colocado em vasos plásticos, de 5 $\mathrm{kg}$, onde permaneceu durante 15 dias incubados até a semeadura do arroz. Durante esse período, mantevese a umidade do solo próximo de $80 \%$ da capacidade de campo.

Para avaliar a reatividade de fontes de silício, utilizaram-se amostras de siligran e silicon aplicadas na forma de pó e granulada (Tabela 3). Tais fontes são de origem natural, sendo a fonte silicon enriquecida com Albright \& Wilson, produto importado de alta solubilidade. Para obtenção dos materiais em pó, os produtos granulados foram moídos e peneirados em peneira de 50 mesh, garantindo assim uma granulometria homogênea para as fontes. Os materiais granulados foram passados em peneira de 10 mesh e retidos na peneira de 20 mesh para também garantir granulometria homogênea dos produtos. Foram utilizados tratamentos adicionais com Wollastonita, fonte considerada como padrão para experimentos com silício.

Tabela 3. Atributos químicos das fontes de Si utilizadas no experimento com arroz

\begin{tabular}{lccrc}
\hline Fontes & Si total & Si solúvel & $\mathrm{CaO}$ & $\mathrm{MgO}$ \\
\cline { 2 - 5 } & & & & \\
\cline { 2 - 5 } & & & & \\
Wollastonita (padrão) & 23,0 & 4,6 & 42,4 & 0,0 \\
Silicon (granulado e pó) & 11,3 & 1,0 & 29,7 & 10,0 \\
Siligran (granulado e pó) & 12,0 & 1,0 & 27,8 & 11,3 \\
\hline
\end{tabular}

Incorporaram-se, ao solo dos vasos, doses crescentes de Wollastonita (50, 100, 200 e $400 \mathrm{mg} \mathrm{kg}^{-}$ $\left.{ }^{1}\right)$ e $200 \mathrm{mg} \mathrm{kg}^{-1}$ de silicon e siligran, em delineamento em blocos casualizados com quatro repetições. As características químicas dos materiais utilizados estão apresentadas na tabela 3. Procedeu-se a adição de carbonato de cálcio $\left(\mathrm{CaCO}_{3}\right)$ e carbonato de magnésio $\left(\mathrm{MgCO}_{3}\right)$ para balancear as diferentes doses de silicato. A adição de $\mathrm{CaCO}_{3}$ e $\mathrm{MgCO}_{3}$ objetivou o equilíbrio dos teores de cálcio e magnésio aplicados, visando isolar o efeito do silício liberado pelas fontes sobre as plantas, já que os materiais utilizados são fontes de $\mathrm{Ca}$ e $\mathrm{Mg}$.

Semeou-se a cultivar de arroz Rio Formoso, adaptada às regiões de Goiás e Tocantins, de ciclo médio, com período da emergência à floração de 95 dias; grão tipo agulhinha; renda de benefício de $65 \%$ e 55\% de grãos inteiros; resistente ao acamamento; moderadamente resistente a brusone na folha e na panícula e moderadamente suscetível à mancha dos grãos (Embrapa, 2004). Após a emergência das plântulas foi realizado o desbaste, deixando-se cinco plantas por vaso. Os vasos foram inundados com água destilada sete dias após a emergência das plântulas, deixando-se uma lâmina de aproximadamente $2,0 \mathrm{~cm}$. A água dos vasos foi mantida no nível estabelecido, durante todo o período do experimento.

As plantas de arroz foram colhidas 185 dias após o plantio, separando-se as panículas do restante da planta. As panículas foram pesadas e, posteriormente, os grãos separados e pesados. Os grãos, por sua vez, foram separados da casca para se determinar o teor de silício, conforme método proposto por KORNDÖRFER et al. (2004a).

A parte aérea (folha + colmo) foi lavada em água destilada, para evitar contaminação com partículas de solo, e seca em estufa a $65{ }^{\circ} \mathrm{C}$ para obtenção da massa seca. Determinou-se o teor de silício da parte aérea (folha + colmo), conforme método proposto por KORNDÖRFER et al. (2004b).

As variáveis analisadas foram submetidas ao teste de Tukey, e as médias comparadas a 5\% de probabilidade. Estabeleceram-se relações entre doses aplicadas de silicatos e teor de nutrientes $(\mathrm{Si}, \mathrm{Ca}, \mathrm{Mg})$ e $\mathrm{pH}$ do solo e teores de Si na parte aérea (folha + colmo), casca e Si acumulado.

\section{RESULTADOS E DISCUSSÃO}

A extração de Si pelo ácido acético revelou valores superiores em relação ao extrator cloreto de cálcio para todas as doses (Figura 1). Esse resultado pode ser observado desde a testemunha até a dose de $400 \mathrm{mg} \mathrm{kg}^{-1}$, concordando com resultados obtidos por Pereira et al. (2004) e Braga (2004) que, trabalhando com doses crescentes de sílica gel nas culturas de arroz e sorgo, também observaram incremento nos teores de Si no solo extraído com ácido acético em comparação ao cloreto de cálcio.

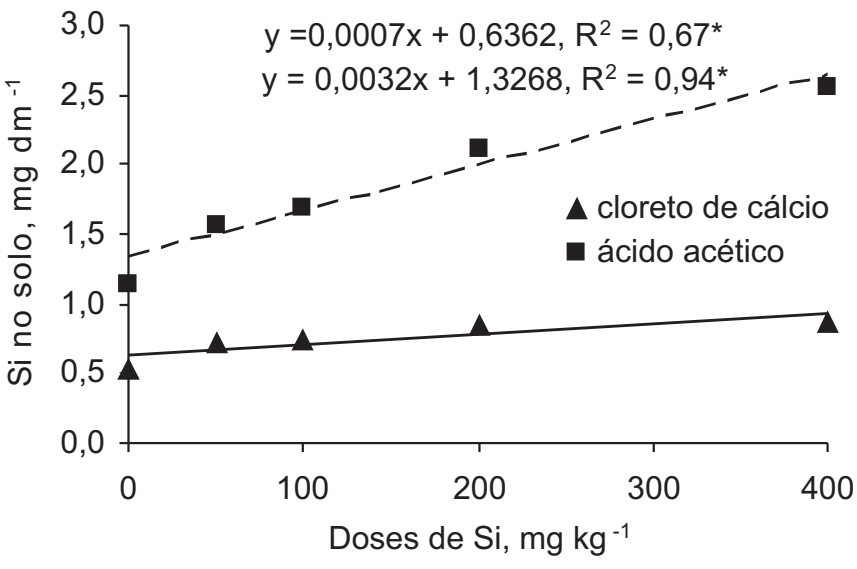

Figura 1. Teores de Si no solo (cloreto de cálcio 0,01 mol $\mathrm{L}^{-1}$ e ácido acético $0,5 \mathrm{~mol} \mathrm{~L}^{-1}$ ) em função da aplicação de doses crescentes de Wollastonita (amostras coletadas após colheita do arroz). 
Comparando-se os tratamentos contendo siligran e silicon, na forma de pó e granulada, com a Wollastonita, na dose de $200 \mathrm{mg} \mathrm{kg}^{-1}$, observa-se que nos teores de silício extraídos do solo não se observaram diferenças significativas, tanto com o extrator cloreto de cálcio quanto pelo ácido acético (Tabela 4).

Comparando-se os extratores, nota-se que o ácido acético extraiu maior quantidade de Si do solo em todas as fontes estudadas. Provavelmente, esse processo ocorreu porque é capaz de extrair formas de Si não disponíveis para as plantas, tais como formas polimerizadas ou mesmo Si presente na fase sólida do solo (argilominerais) superestimando os valores de silício em solução (Queiroz, 2003; Braga, 2004; Vidal, 2005).

Tabela 4. Teor de Si no solo em função de fontes e extratores após colheita

\begin{tabular}{|c|c|c|c|}
\hline Fontes & $\begin{array}{c}\text { Dose de } \\
\text { Si }\end{array}$ & $\begin{array}{c}\text { Si-Ca Cl }{ }_{2} \\
0,01 \mathrm{~mol} \mathrm{~L}^{-1}\end{array}$ & $\begin{array}{c}\text { Si-Ac. Acético } \\
0,5 \mathrm{~mol} \mathrm{~L}^{-1}\end{array}$ \\
\hline & $\mathrm{mg} \mathrm{kg}^{-1}$ & \multicolumn{2}{|c|}{$\mathrm{mg} \mathrm{dm}^{-3}$} \\
\hline Testemunha & 0 & $0,5 \mathrm{~b}$ & $1,1 \mathrm{~b}$ \\
\hline Wollastonita & 200 & $0,9 \mathrm{a}$ & $2,1 \mathrm{a}$ \\
\hline Siligran granulado & 200 & $0,6 \mathrm{ab}$ & $2,0 \mathrm{a}$ \\
\hline Siligran pó & 200 & $0,7 \mathrm{ab}$ & $2,3 \mathrm{a}$ \\
\hline Silicon granulado & 200 & $0,6 \mathrm{ab}$ & $1,9 \mathrm{ab}$ \\
\hline Silicon pó & 200 & $0,6 \mathrm{ab}$ & $1,8 \mathrm{ab}$ \\
\hline C.V. \% & & 18,4 & 19,4 \\
\hline DMS & & 0,3 & 0,8 \\
\hline
\end{tabular}

*Médias seguidas por letras iguais na coluna não diferem entre si pelo teste de Tukey a $5 \%$ de probabilidade.

Não houve diferença significativa para $\mathrm{pH}, \mathrm{Ca}$ e Mg trocáveis do solo entre as fontes testadas (Tabela 5). Esses resultados eram esperados, já que houve o balanceamento das bases antes da semeadura. Esse efeito é muito importante, assegurando que as diferenças entre os tratamentos se devem ao efeito isolado do silício, não havendo interferência do $\mathrm{pH}, \mathrm{Ca}$ e $\mathrm{Mg}$ na reatividade e comparação dos produtos testados.

A aplicação de Wollastonita aumentou a disponibilidade de Si no solo (Figura 1), o qual foi absorvido pelo sistema radicular do arroz e se acumulou no tecido foliar (Figura 2A). À medida que se aumentou a dose de Wollastonita de $50 \mathrm{mg} \mathrm{kg}^{-1}$ para $400 \mathrm{mg} \mathrm{kg}^{-1} \mathrm{de} \mathrm{Si}$ aumentaram-se os teores de Si na parte aérea (talo + colmo) e casca do arroz (Figura 2A e B), corroborando com dados obtidos por PEREIRA et al. (2004) e Braga (2004). FAria (2000), estudando a tolerância do arroz-de-sequeiro ao déficit hídrico em Neossolo Quartzarênico, obteve resposta linear da aplicação de doses crescentes de silicato de cálcio sobre os teores de silício na parte aérea das plantas, com teores do elemento variando de 9,0 a $21,0 \mathrm{~g} \mathrm{~kg}^{-1}$ nesse solo, respectivamente, para doses de 0 a $600 \mathrm{~kg} \mathrm{ha}^{-1}$.

A quantidade de Si acumulado passou de 0,2 $\mathrm{g} \mathrm{vaso}^{-1}$ da testemunha, sem $\mathrm{Si}$, para $0,7 \mathrm{~g} \mathrm{vaso}^{-1}$ na maior dose de Wollastonita, $400 \mathrm{mg} \mathrm{kg}^{-1}$ (Figura 3).

Ambos os extratores (ácido acético e cloreto de cálcio) foram capazes de quantificar o Si disponível, quando se usaram doses crescentes de Wollastonita, isto é, quanto maior o teor de $\mathrm{Si}$ no solo maior foi o $\mathrm{Si}$ acumulado nas plantas de arroz. Apesar disso, percebe-se que o extrator ácido acético apresentou coeficiente de determinação superior $\left(R^{2}=0,87\right)$ ao do cloreto de cálcio $\left(\mathrm{R}^{2}=0,76\right)$ para analisar o $\mathrm{Si}$ disponível (Figura 4 A e B). Esses resultados concordam com Korndörfer et al. (1999) que, trabalhando com a cultura do arroz de sequeiro em quatro solos da região do Triângulo Mineiro, obteve maior correlação entre o Si extraído do solo e o $\mathrm{Si}$ acumulado nas plantas pelo ácido acético. Segundo o autor, esse extrator é de fácil preparo e possui um custo de reagente bem baixo, facilitando seu uso em análises de rotina.

Tabela 5. Valores de $\mathrm{pH}, \mathrm{Ca}$ e Mg trocáveis determinados nas amostras de solo coletadas após colheita do arroz submetido a diferentes fontes de silício

\begin{tabular}{|c|c|c|c|c|}
\hline Fontes & Dose de Si & $\mathrm{pH} \mathrm{CaCl} 2$ & \multicolumn{2}{|c|}{$\mathrm{KCl} 1 \mathrm{~mol} \mathrm{~L}^{-1}$} \\
\hline & $\mathrm{mg} \mathrm{kg}^{-1}$ & & \multicolumn{2}{|c|}{$-\mathrm{mmol}_{\mathrm{c}} \mathrm{dm}^{-3}$} \\
\hline Testemunha & 0 & 4,1 & 2,0 & 0,5 \\
\hline Wollastonita & 50 & 4,1 & 2,0 & 0,4 \\
\hline Wollastonita & 100 & 4,2 & 3,0 & 0,5 \\
\hline Wollastonita & 200 & 4,2 & 3,0 & 0,6 \\
\hline Wollastonita & 400 & 4,4 & 5,0 & 0,5 \\
\hline Siligran granulado & 200 & 4,4 & 4,0 & 1,0 \\
\hline Siligran pó & 200 & 4,5 & 6,0 & 1,0 \\
\hline Silicon granulado & 200 & 4,4 & 3,0 & 1,1 \\
\hline Silicon pó & 200 & 4,3 & 3,0 & 0,9 \\
\hline
\end{tabular}



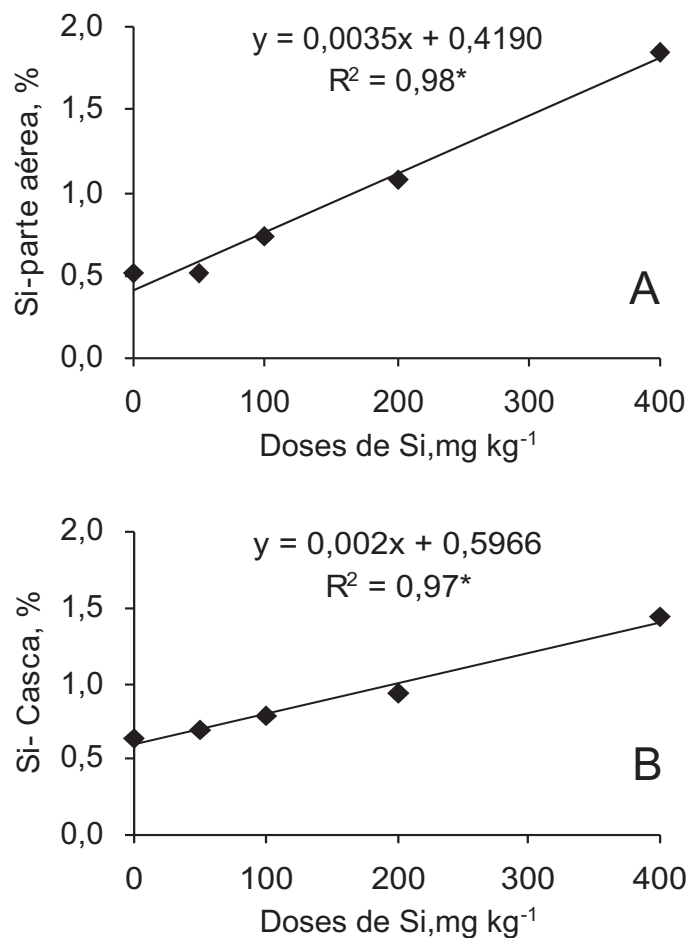

Figura 2. Teores de Si na parte aérea (folha + colmo) do arroz e casca do arroz.

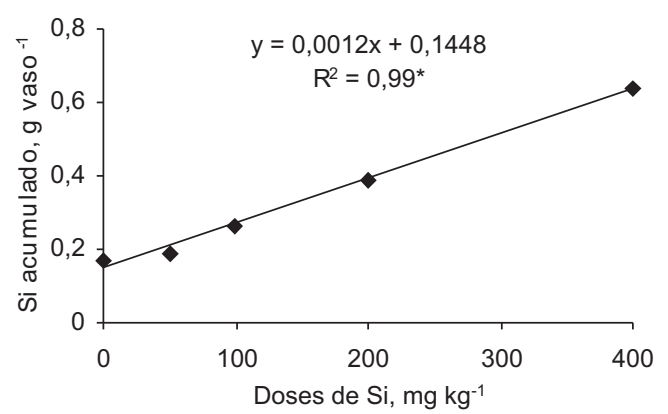

Figura 3. Teor de Si acumulado na parte aérea do arroz em função da aplicação de doses crescentes de Wollastonita.

É importante destacar que a maior correlação se deve, em parte, à capacidade do extrator (ácido acético) em dissolver o Si da fonte aplicada no solo. Neste caso, a acidez do extrator pode contribuir na dissolução do silicato que ainda não reagiu no solo e, assim, determinar o Si que não é disponível, superestimando os resultados obtidos. A maior capacidade de extração do ácido acético pode também ajudar a explicar a maior correlação, tende em vista que os erros analíticos são os mesmos quanto maior os valores de Si extraído.
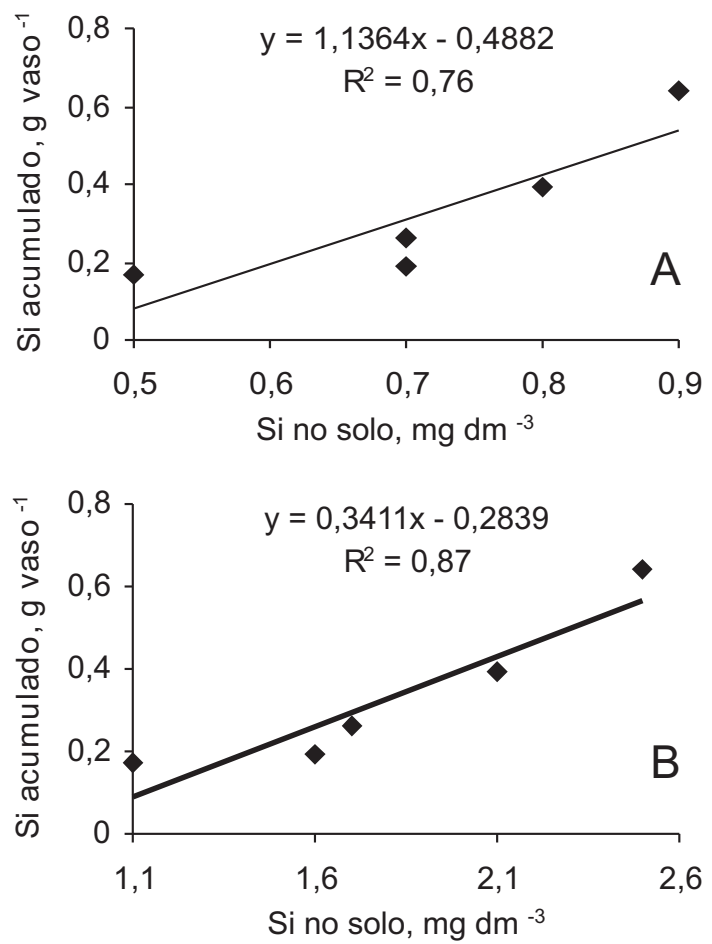

Figura 4. Acúmulo de Si na parte aérea do arroz em função do extrator utilizado - (A - Si cloreto de cálcio $0,01 \mathrm{~mol} \mathrm{~L}^{-1} ; \mathrm{B}$ - Si ácido acético $\left.0,5 \mathrm{~mol} \mathrm{~L}^{-1}\right)$.

Para o teor de Si na parte aérea, não ocorreu diferença significativa entre a Wollastonita e as fontes siligran (granulada e pó) e silicon pó, sendo todas superiores à testemunha (Tabela 6). Considerando os teores de Si na casca do arroz, a Wollastonita não apresentou diferença significativa do siligran pó, sendo superior à testemunha e às demais fontes (Tabela 6). Não houve diferenças significativas entre as fontes quanto aos teores de $\mathrm{Si}$ acumulados na parte aérea do arroz, sendo todas superiores à testemunha (Tabela 6). Para massa seca, houve diferença estatística entre Wollastonita e as fontes siligran granulado e silicon granulado (Tabela 6). SiLVA (2002), estudando fontes de silício, obteve resultados superiores da Wollastonita em relação à fonte siligran na forma de pó e granulada, decorrente da maior solubilidade da fonte-padrão.

As fontes de Si não diferiram entre si com relação à massa fresca de panículas, isto é, foram todas iguais (Tabela 7). Considerando apenas a produção de grãos, a única diferença observada foi em relação à forma aplicada do produto silicon. $\mathrm{O}$ produto em pó foi mais eficiente que o produto granulado; os valores aumentaram de 17,2 $\mathrm{g} \mathrm{vaso}^{-1}$, na forma de grânulo, para $22,1 \mathrm{~g}$ vaso $^{-1}$ na forma de pó, o que indica maior eficiência na disponibilização de silício quando da aplicação do produto em pó (Tabela 7). 
Tabela 6. Teores de Si na parte aérea (folha + colmo), casca e Si acumulado nas plantas de arroz submetidas à aplicação de diferentes fontes de Si

\begin{tabular}{lccccc}
\hline Fontes & Dose de Si & Massa seca total & Si parte aérea & Si casca & Si acumulado \\
\hline & $\mathrm{mg} \mathrm{kg}^{-1}$ & $\mathrm{~g} \mathrm{vas0^{-1 }}$ & $0,17 \mathrm{~b}$ & $0,52 \mathrm{c}$ & $0,64 \mathrm{bc}$ \\
Testemunha & 0 & $32,2 \mathrm{ab}$ & $1,08 \mathrm{a}$ & $0,93 \mathrm{a}$ & $0,39 \mathrm{a}$ \\
Wollastonita & 200 & $36,2 \mathrm{a}$ & $1,00 \mathrm{ab}$ & $0,61 \mathrm{bc}$ & $0,31 \mathrm{ab}$ \\
Siligran granulado & 200 & $31,4 \mathrm{~b}$ & $0,98 \mathrm{ab}$ & $0,77 \mathrm{ab}$ & $0,32 \mathrm{ab}$ \\
Siligran pó & 200 & $32,6 \mathrm{ab}$ & $0,78 \mathrm{bc}$ & $0,64 \mathrm{bc}$ & $0,24 \mathrm{ab}$ \\
Silicon granulado & 200 & $31,1 \mathrm{~b}$ & $0,96 \mathrm{ab}$ & $0,55 \mathrm{c}$ & $0,32 \mathrm{ab}$ \\
Silicon pó & 200 & $33,1 \mathrm{ab}$ & 13,43 & 12,22 & 23,84 \\
CV (\%) & & 5,44 & 0,3 & 0,2 & 0,2 \\
DMS & & 4,1 &
\end{tabular}

*Médias seguidas por letras iguais na coluna não diferem entre si pelo teste de Tukey a 5\% de probabilidade.

As doses de Si não influenciaram na massa fresca de panículas, produção de massa seca total e produtividade de grãos quando foi usada a fontepadrão Wollastonita (Tabela 8).

A falta de resposta à aplicação de Si sobre essas variáveis se deve ao fato de o experimento ter sido desenvolvido em casa de vegetação, onde não existe nenhum tipo de estresse para a planta, isto é, não houve falta de água, nem ataque de pragas e incidência de doenças.

Tabela 7. Massa fresca das panículas (colheita), produção de grãos e de massa secca CQNG plantas dêES arroz em função da utilização de diferentes fontes

\begin{tabular}{lccc}
\hline Fontes & Dose de Si & Massa fresca panículas & Produtividade de grãos \\
\cline { 2 - 4 } Testemunha & $\mathrm{mg} \mathrm{kh}^{-1}$ & & g vaso $^{-1}$ \\
Wollastonita & 0 & $22,8 \mathrm{a}$ & $19,9 \mathrm{ab}$ \\
Siligran granulado & 200 & $22,8 \mathrm{a}$ & $21,3 \mathrm{ab}$ \\
Siligran pó & 200 & $21,8 \mathrm{a}$ & $18,2 \mathrm{ab}$ \\
Silicon granulado & 200 & $20,5 \mathrm{a}$ & $17,8 \mathrm{ab}$ \\
Silicon pó & 200 & $19,5 \mathrm{a}$ & $17,2 \mathrm{~b}$ \\
CV (\%) & 200 & $25,0 \mathrm{a}$ & $22,1 \mathrm{a}$ \\
DMS & & 11,99 & 10,88 \\
\end{tabular}

*Médias seguidas por letras iguais na coluna não diferem entre si pelo teste de Tukey ao nível de 5\% de probabilidade.

Tabela 8. Massa fresca das panículas (colheita), produtividade de grãos e de massa seca total das plantas de arroz em função da utilização de doses de Wollastonita

\begin{tabular}{lcccc}
\hline Fonte & Dose de Si & Massa seca total & Produtividade de grãos & Massa fresca de panículas \\
\cline { 2 - 5 } Testemunha & $\mathrm{mg} \mathrm{kg}^{-1}$ & 32,23 & g vaso $^{-1}$ & 20,63 \\
Wollastonita & 0 & 37,01 & 19,96 & 22,76 \\
Wollastonita & 50 & 34,93 & 23,54 & 26,10 \\
Wollastonita & 100 & 36,22 & 21,62 & 22,83 \\
Wollastonita & 200 & 34,65 & 20,68 & 22,01 \\
\hline
\end{tabular}


1. A fonte-padrão Wollastonita proporcionou comportamento linear, aumentando o Si disponível no solo e a absorção pelo arroz com o aumento das doses aplicadas.

2. Os maiores aumentos, nos teores de Si na parte aérea, casca, Si acumulado e na massa seca total foram proporcionados pela Wollastonita;

3. A fonte com maior aumento na produtividade de grãos foi silicon na forma de pó.

4. O extrator ácido acético extraiu maiores quantidade de Si do solo em relação ao cloreto de cálcio, superestimando os resultados.

\section{REFERÊNCIAS}

BRAGA, A.M.C. Eficiência de fontes e doses de fertilizantes contendo silício na adubação do arroz inundado e do sorgo. 2004. 123f. Dissertação (Mestrado em Solos e Nutrição de Plantas) - Instituto de Ciências Agrárias, Universidade Federal de Uberlândia, Uberlândia, MG, 2004.

EPSTEIN, E. The anomaly of silicon in plant biology. Proceedings of National Academy of Sciences of the United States of America, Washington, v.91, n.1, p.11-17, 1994.

EMBRAPA. EMPRESA BRASILEIRA DE PESQUISA AGROPECUÁRIA. Embrapa Arroz e Feijão. Brasília, 28 dez. 2004. Disponível em: http://www.cnpaf.embrapa.br/ index.htm. Acesso em 20 dez. 2004.

EMBRAPA. EMPRESA BRASILEIRA DE PESQUISA AGROPECUÁRIA.Centro Nacional de Pesquisa de Solos (Rio de Janeiro- RJ). Manual de Métodos de Análise de Solo. 2 ed. ver. atual. Rio de Janeiro, 1999. 212p.

FARIA, R.J. Influência do silicato de cálcio na tolerância do arroz de sequeiro ao déficit hídrico do solo. 2000. $47 \mathrm{f}$. Dissertação (Mestrado em solos e nutrição de plantas)Universidade Federal de Lavras, Lavras, MG, 2000.

KORNDÖRFER, G.H.; PEREIRA, H.S.; CAMARGO, M.S. Silicatos de cálcio e magnésio na agricultura. 3 ed. Uberlândia: GPSi/ICIAG/UFU, 2004a. 23p. (Boletim Técnico, 01)

KORNDÖRFER, G.H.; PEREIRA. H.S.; NOLLA. A. Análise de silício: solo, planta e fertilizante. Uberlândia: GPSi/ICIAG/ UFU, 2004b. 34 p. (Boletim Técnico, 2)

KORNDÖRFER G.H.; COELHO, N.M.; SNYDER, G.H.; MIZUTANI, C.T. Avaliação de métodos de extração de silício em solos cultivados com arroz de sequeiro. Revista Brasileira de Ciência do Solo, Viçosa, v.23 n.1, p.101-106, 1999.

MA, J.F.; MIYAKE, Y.; TAKAHASHI, E. Silicon as a beneficial element for crop plants. In: DATNOFF, L.E.; SNYDER, G.H.; KORNDÖRFER, G.H. Silicon in agriculture. Amsterdam: Elsevier, 2001. p.17-39.

MARSCHNER, H. Mineral nutrition of higher plants. London: Academic Press, 1995. 889p.
PEREIRA, H.S.; KONDÖRFER, G.H.; VIDAL, A.A.; CAMARGO, M.S. Fontes de silício para a cultura do arroz. Scientia Agricola, Piracicaba v.16, n.5, p.522-528, 2004.

QUEIROZ, A.A. Reação de fontes de silício em quatro solos do cerrado. 2003. 39f. Monografia (Graduação em agronomia)Instituto de Ciências Agrárias - Universidade Federal de Uberlândia, Uberlândia, MG, 2003.

SANTOS, G.R.; KORNDÖRFER, G.H.; REIS FILHO, J.C.D.; PELÚZIO, J.M.. Adubação com silício: influência sobre as principais doenças e sobre a produtividade do arroz irrigado por inundação. Revista Ceres, Viçosa, v. 50, n.287, p.1-8, 2003.

SILVA, M.F.Avaliação de fontes de silício através de testes biológicos e de incubação. 2002. 42 f. Monografia (Graduação em Agronomia)- Instituto de Ciências Agrárias - Universidade Federal de Uberlândia, Uberlândia, MG, 2002.

VIDAL, A. Efeito do pH na solubilidade de silício em solos da região do Triângulo Mineiro. 2005. 69f. Dissertação (Mestrado em Agronomia) - Universidade Federal de Uberlândia, Uberlândia, MG, 2005. 